\title{
Article \\ Extracellularly Released Calreticulin Induced by Endoplasmic Reticulum Stress Impairs Syncytialization of Cytotrophoblast Model BeWo Cells
}

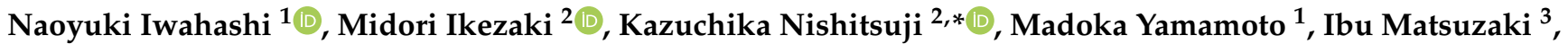 \\ Naoki Kato ${ }^{2}$, Naoyuki Takaoka ${ }^{2}$, Mana Taniguchi ${ }^{2}$, Shin-ichi Murata ${ }^{3}$, Kazuhiko Ino ${ }^{1}$ and Yoshito Ihara $^{2, *(D)}$ \\ 1 Department of Obstetrics and Gynecology, Wakayama Medical University School of Medicine, \\ 811-1 Kimiidera, Wakayama 641-8509, Japan; naoyuki@wakayama-med.ac.jp (N.I.); \\ madoka-y@wakayama-med.ac.jp (M.Y.); kazuino@wakayama-med.ac.jp (K.I.) \\ 2 Department of Biochemistry, Wakayama Medical University School of Medicine, 811-1 Kimiidera, \\ Wakayama 641-8509, Japan; ikezaki@wakayama-med.ac.jp (M.I.); hwhbg038@yahoo.co.jp (N.K.); \\ g.200swimmer@gmail.com (N.T.); qscbbv27476@gmail.com (M.T.) \\ 3 Department of Human Pathology, Wakayama Medical University School of Medicine, 811-1 Kimiidera, \\ Wakayama 641-8509, Japan; m_ibu@wakayama-med.ac.jp (I.M.); smurata@wakayama-med.ac.jp (S.-i.M.) \\ * Correspondence: nishit@wakayama-med.ac.jp (K.N.); y-ihara@wakayama-med.ac.jp (Y.I.); \\ Tel.: +81-73-441-0628 (K.N. \& Y.I.)
}

check for updates

Citation: Iwahashi, N.; Ikezaki, M.; Nishitsuji, K.; Yamamoto, M.; Matsuzaki, I.; Kato, N.; Takaoka, N.; Taniguchi, M.; Murata, S.-i.; Ino, K.; et al. Extracellularly Released Calreticulin Induced by Endoplasmic Reticulum Stress Impairs Syncytialization of Cytotrophoblast Model BeWo Cells. Cells 2021, 10, 1305. https://doi.org/10.3390/ cells10061305

Academic Editor:

Dimitrios Karamichos

Received: 28 April 2021

Accepted: 21 May 2021

Published: 24 May 2021

Publisher's Note: MDPI stays neutral with regard to jurisdictional claims in published maps and institutional affiliations.

Copyright: (c) 2021 by the authors. Licensee MDPI, Basel, Switzerland. This article is an open access article distributed under the terms and conditions of the Creative Commons Attribution (CC BY) license (https:/ / creativecommons.org/licenses/by/ $4.0 /)$.

\begin{abstract}
The pregnancy-specific syndrome preeclampsia is a major cause of maternal mortality throughout the world. The initial insult resulting in the development of preeclampsia is inadequate trophoblast invasion, which may lead to reduced maternal perfusion of the placenta and placental dysfunction, such as insufficient trophoblast syncytialization. Endoplasmic reticulum (ER) stress has been implicated in the pathology of preeclampsia and serves as the major risk factor. Our previous studies suggested critical roles of calreticulin (CRT), which is an ER-resident stress response protein, in extravillous trophoblast invasion and cytotrophoblast syncytialization. Here, we studied the mechanism by which ER stress exposes the placenta to the risk of preeclampsia. We found that CRT was upregulated in the serum samples, but not in the placental specimens, from preeclamptic women. By using BeWo cells, an established model of cytotrophoblasts that syncytialize in the presence of forskolin, we demonstrated that thapsigargin-induced ER stress caused extracellular release of CRT from BeWo cells and that the extracellular CRT suppressed forskolin-induced release of $\beta$-human chorionic gonadotropin and altered subcellular localization of E-cadherin, which is a key adhesion molecule associated with syncytialization. Our results together provide evidence that induction of ER stress leads to extracellular CRT release, which may contribute to placental dysfunction by suppressing cytotrophoblast syncytialization.
\end{abstract}

Keywords: calreticulin; syncytialization; trophoblast; preeclampsia; endoplasmic reticulum stress

\section{Introduction}

The placenta in humans is critical for embryonic development and pregnancy maintenance. The placenta and associated extraembryonic membranes are extraembryonic structures of the conceptus and form from the zygote at the initial stage of pregnancy. The trophectoderm, the precursor of all trophoblast cells, is the first epithelium that appears during mammalian embryogenesis; it is a polarized single-cell layer that makes up the blastocyst wall. During embryogenesis, the trophectoderm forms the cytotrophoblasts (CTBs), or epithelial "stem cells" of the placenta, that differentiate into two major placental cell types: extravillous trophoblasts (EVTs) and syncytiotrophoblasts (STBs) [1]. The EVTs are involved in uterine artery remodeling, which is crucial for perfusion of the placenta with maternal blood; CTBs undergo syncytialization to form multinucleated STBs that are essential for nutrient and gas exchange at the maternal-fetal interface and for hormone 
synthesis to support the pregnancy [2-4]. Dysfunction of the CTB syncytialization may result in pregnancy-related pathologies such as preeclampsia, which is characterized by hypertension, proteinuria, and edema and is a major cause of maternal death [5-7].

The detailed molecular mechanisms of the development and progression of preeclampsia are not fully understood. Some data have suggested the involvement of endoplasmic reticulum (ER) stress in the pathogenesis of human pregnancy complications including preeclampsia [8-11]. Although inadequate placentation has been suggested to result in the induction of ER stress [12], how ER stress contributes to preeclampsia development is unknown. We previously showed that calreticulin (CRT), an ER-resident molecular chaperone that is ubiquitously expressed throughout the body including the placenta $[13,14]$, is necessary for both adequate invasion of EVTs and syncytialization of CTBs $[15,16]$. Certain studies reported increases in CRT mRNA and protein levels in maternal blood and placentas from preeclamptic patients [12,13]. Although CRT is a classical ER-resident chaperone, it has been observed outside the ER, cell surface, and extracellular compartments, and it regulates various biological processes such as uptake by dendritic cells or phagocytosis of CRT-expressing cancer cells and apoptotic cells [17,18], cell migration, and cell proliferation [19-23]. Extracellular release of CRT is an unusual event, however, and because CRT is a stress response protein, ER stress may be involved in the extracellular release of CRT [24] Adding exogenous Escherichia coli-expressed human CRT to the culture medium for the HTR8/SVneo human trophoblast cell line reportedly reduced cell migration [25]. These lines of evidence prompted us to study whether ER stress induces extracellular release of CRT from CTBs and whether this extracellular CRT affects the functions of CTBs, such as syncytialization.

We found here that serum CRT levels were significantly higher in preeclamptic patients than in women with normal pregnancies. We used thapsigargin as an ER stress inducer and human choriocarcinoma BeWo cells as a CTB model, and we discovered that extracellular CRT was released as a result of ER stress in BeWo cells. The extracellularly released CRT reduced forskolin-stimulated release of $\beta$-human chorionic gonadotropin ( $\beta$-hCG) and altered the cell surface localization of E-cadherin, which is a cell-cell adhesion protein and is thus critical for CTB syncytialization [26]. On the basis of our results, we thus propose a novel non-ER function of CRT that may contribute to dysfunctional placentation and the development of preeclampsia.

\section{Materials and Methods}

\subsection{Materials}

The anti-CRT antibody, anti-calnexin antibody, anti-immunoglobulin-binding protein (BiP) antibody, and anti-ER-resident protein 57 (ERp57) antibody were obtained from Stressgen Biotechnologies (San Diego, CA, USA). The anti-E-cadherin antibody, anti- $\beta$ catenin antibody, anti-glyceraldehyde-3-phosphate dehydrogenase (GAPDH) antibody, and anti-Golgi matrix protein of $130 \mathrm{kDa}$ (GM130) antibody were from BD Biosciences (San Jose, CA, USA), Sigma-Aldrich (St. Louis, MO, USA), Merck Millipore (Burlington, MA, USA), and Abcam (Cambridge, UK), respectively.

\subsection{Human Tissue Collection and Sample Preparation}

We obtained informed consent from individual patients for the use of the placental specimens. Third-trimester samples of human placenta were collected during performance of cesarean sections before the onset of labor. Preeclampsia was defined as having a blood pressure reading of $\geq 140 / 90 \mathrm{mmHg}$ after 20 weeks of gestation plus proteinuria ( $\geq 300 \mathrm{mg}$ of protein $/ 24 \mathrm{~h}$ ). The eligibility of the preeclampsia cases was determined on the basis of the diagnostic criteria of the International Society for the Study of Hypertension in Pregnancy. Cases involving intrauterine growth retardation, multiple pregnancies, fetal chromosomal abnormalities, or fetal anomalies were excluded. For immunoblot analysis, we collected specimens of placentas from patients with preeclampsia $(n=6)$ and women with gestational age-matched normal pregnancies $(n=6)$, as well as serum samples 
from healthy nonpregnant women $(n=6)$, women with gestational age-matched normal pregnancies $(n=6)$, and patients with preeclampsia $(n=6)$. The patients used in the immunoblot analysis are included in Table 1. Placental specimens and serum samples were immediately frozen in liquid nitrogen and stored at $-80^{\circ} \mathrm{C}$ before being used for analysis. This study was approved by the Ethics Committee of Wakayama Medical University.

Table 1. Clinical characteristics of the study population.

\begin{tabular}{cccc}
\hline & Normal Pregnancy & Preeclampsia Alone & $p$ Value \\
\hline Characteristic & $(\mathrm{n}=22)$ & $(\mathrm{n}=18)$ & \\
\hline $\begin{array}{c}\text { Maternal age (years) } \\
\text { Prepregnancy body mass index } \\
\left(\mathrm{kg} / \mathrm{m}^{2}\right)\end{array}$ & $30.4 \pm 5.5$ & $32.8 \pm 4.6$ & $\mathrm{~ns}$ \\
Gestational age at delivery & $20.7 \pm 2.6$ & $25.5 \pm 5.9$ & $<0.001$ \\
$\quad($ weeks) & $34.7 \pm 4.2$ & $34.2 \pm 2.6$ & $\mathrm{~ns}$ \\
Neonatal weight $(\mathrm{g})$ & $2447 \pm 712$ & $2232 \pm 614$ & $\mathrm{~ns}$ \\
Placental weight $(\mathrm{g})$ & $528 \pm 133$ & $512 \pm 129$ & $\mathrm{~ns}$ \\
\hline
\end{tabular}

\subsection{Immunohistochemistry}

Paraffin-embedded blocks of placental tissue samples (patients with preeclampsia: $\mathrm{n}=18$; gestational age-matched controls: $\mathrm{n}=22$ ) were cut into 3 - $\mu$ m-thick sections, deparaffinized, and rehydrated. We then blocked endogenous peroxidase activity with $0.3 \%$ hydrogen peroxide in methanol. For antigen retrieval, we boiled the slides in $1 \mathrm{mM}$ ethylenediaminetetraacetic acid ( $\mathrm{pH} \mathrm{8.0)} \mathrm{in} \mathrm{a} \mathrm{pressure} \mathrm{cooker} \mathrm{for} 10 \mathrm{~min}$. We incubated the sections with an anti-CRT antibody (Abcam) at a dilution of 1:5000. We detected signals by using the simple stain MAX-PO reagent (Nichirei Biosciences, Tokyo, Japan) and 3,3-diaminobenzidine as the substrate. We used Mayer's hematoxylin solution for counterstaining and scored the staining intensity as $0=$ none, $1=$ weak, $2=$ moderate, and $3=$ strong staining. We graded the percentage of positive cells as 0 : no positive cells, $1:<30 \%, 2$ : $30-80 \%$, or $3:>80 \%$ and then used the following equation to calculate the immunoreactive score $($ IRS): IRS $=$ staining intensity $\times$ percentage of positive cells, according to previous reports $[16,27]$.

\subsection{Cell Culture}

Human choriocarcinoma BeWo cells, which are commonly used as a model of trophoblast differentiation and syncytialization $[5,28]$ ), were purchased from the American Type Culture Collection (Manassas, VA, USA) and were authenticated by the JCRB Cell Bank (National Institute of Biomedical Innovation-Japan, Report No. KBN0410). BeWo cells were grown in Roswell Park Memorial Institute RPMI 1640 medium (Wako Pure Chemicals, Osaka, Japan) supplemented with 10\% fetal calf serum (BioWest, Nuaillé, France) and penicillin, streptomycin, and amphotericin B (Life Technologies, Carlsbad, CA, USA) at $37{ }^{\circ} \mathrm{C}$ in $5 \% \mathrm{CO}_{2}$ and $95 \%$ air.

\subsection{Reverse Transcription-Polymerase Chain Reaction (RT-PCR)}

Total RNA was collected and reverse-transcribed by using PrimeScript One Step RT-PCR Kit Ver. 2 (TaKaRa Biomedicals, Shiga, Japan). Polymerase chain reactions were performed by using the following cycling parameters: for human X-box-binding protein-1 (XBP-1): 25 cycles at $94{ }^{\circ} \mathrm{C}$ for $0.5 \mathrm{~min}$, at $65{ }^{\circ} \mathrm{C}$ for $0.5 \mathrm{~min}$, and at $72{ }^{\circ} \mathrm{C}$ for $1 \mathrm{~min}$; for human GAPDH: 20 cycles at $94{ }^{\circ} \mathrm{C}$ for $0.5 \mathrm{~min}$, at $56{ }^{\circ} \mathrm{C}$ for $0.5 \mathrm{~min}$, and at $72{ }^{\circ} \mathrm{C}$ for $1 \mathrm{~min}$. The primer sequences were as follows: for humanXBP-1: forward 5'-GCT GAA GAG GAG GCG GAA G-3', reverse 5'-GTC CAG AAT GCC CAA CAG G-3'; for human GAPDH: forward 5'-GGA TTT GGT CGT ATT GGG CG-3', reverse 5'-CAG TAG AGG CAG GGA TGA TG-3'. We analyzed the transcripts by using $8 \%$ polyacrylamide gel electrophoresis for XBP-1 and 1.5\% agarose gel electrophoresis for GAPDH followed by ethidium bromide staining. GAPDH served as a reference RNA. 


\subsection{Immunodepletion}

BeWo cells were treated with thapsigargin (25-500 nM, Wako Pure Chemicals) for $1 \mathrm{~h}$ at $37^{\circ} \mathrm{C}$, after which cells were washed and culture media were replaced with fresh Opti-MEM (Thermo Fisher Scientific, Waltham, MA, USA). After a 24 -h culture at $37^{\circ} \mathrm{C}$, we collected the conditioned medium [thapsigargin-conditioned medium (Tg-CM)]. For immunodepletion of CRT from Tg-CM, CRT was immunoprecipitated by using anti-CRT antibody that was conjugated with Dynabeads Protein G (Thermo Fisher Scientific). We used the supernatants as CRT-depleted Tg-CM. The absence of CRT in supernatants was confirmed by immunoblot analysis (data not shown). Purified rabbit IgG (Thermo Fisher Scientific) served as an isotype control.

\subsection{Immunoblot Analysis}

We used a Teflon homogenizer (AS ONE Corporation, Osaka, Japan) to homogenize 500-mg samples of human placental tissues in $0.4 \mathrm{~mL}$ of RIPA buffer (Sigma-Aldrich) containing the protease inhibitors $4 \mathrm{mM}$ Pefabloc, $1 \mu \mathrm{M}$ pepstatin, $1 \mu \mathrm{M}$ leupeptin, and $200 \mu \mathrm{M}$ phenylmethylsulfonyl fluoride (Roche, Basel, Switzerland). Samples were then centrifuged at $18,000 \times g$ for $10 \mathrm{~min}$ at $4{ }^{\circ} \mathrm{C}$, and supernatants were collected and subjected to immunoblot analysis as described below. To induce ER stress, we treated BeWo cells with thapsigargin (25-500 nM) for $1 \mathrm{~h}$ at $37^{\circ} \mathrm{C}$, and we analyzed the induction of ER stress by using immunoblotting with anti-phosphorylated or anti-pan-eukaryotic translation initiation factor $2 \alpha$ antibodies (Cell Signaling Technology, Danvers, MA, USA). For cell-based assays, we treated BeWo cells with Tg-CM or CRT-depleted Tg-CM for $24 \mathrm{~h}$ at $37^{\circ} \mathrm{C}$ in the presence of forskolin ( $80 \mu \mathrm{M}$, Sigma-Aldrich). Cells were then lysed in lysis buffer A (10 mM Tris$\mathrm{HCl}$ ( $\mathrm{pH} 7.5), 150 \mathrm{mM} \mathrm{NaCl}, 1 \%$ Nonidet P-40, and protease inhibitors). Cell lysates were sonicated intermittently on ice for $15 \mathrm{~min}$ and then centrifuged at $10,000 \times g$ for $10 \mathrm{~min}$ at $4{ }^{\circ} \mathrm{C}$. Supernatants were separated by using $10 \%$ sodium dodecyl sulfate-polyacrylamide gel electrophoresis and were then transferred to polyvinylidene difluoride membranes (Immobilon-P; Merck Millipore). For analysis of serum samples, each sample was diluted with tris-buffered saline ( $\mathrm{pH} 7.6$ ) to obtain the final protein concentration of $10 \mu \mathrm{g} / \mu \mathrm{L}$, and $100 \mu \mathrm{g}$ proteins were applied to each well of $10 \%$ sodium dodecyl sulfate-polyacrylamide gels. Protein concentrations of nondiluted serum samples are shown in Supplemental Table S1. Membranes were blocked with the EzBlock Chemi blocking solution (ATTO, Tokyo, Japan) and were incubated with primary antibodies at $4{ }^{\circ} \mathrm{C}$ overnight followed by incubation with peroxidase-conjugated secondary antibodies (Cell Signaling Technology). Signals were detected by using the Immobilon Western Chemiluminescent Horseradish Peroxidase substrate (Merck Millipore) and were densitometrically quantified by using ImageJ version 1.50b (National Institutes of Health, Bethesda, MD, USA). GAPDH served as a loading control.

\subsection{Cytotoxicity of Thapsigargin Treatment}

We analyzed cytotoxicity by means of the lactate dehydrogenase (LDH) release assay. We treated BeWo cells with thapsigargin $(25-500 \mathrm{nM})$ for $1 \mathrm{~h}$ at $37^{\circ} \mathrm{C}$ and measured LDH release into culture media by using the MTX-LDH kit (Kyokuto Pharmaceutical, Tokyo, Japan).

\subsection{Immunocytochemistry and Determination of Fusion Index}

BeWo cells were grown on coverslips cultured for $24 \mathrm{~h}$, after which cells were treated with Tg-CM or CRT-depleted Tg-CM for $24 \mathrm{~h}$ at $37^{\circ} \mathrm{C}$ in the presence of forskolin $(80 \mu \mathrm{M})$. Cells were then fixed with $4 \%$ paraformaldehyde in PBS for 20 min at room temperature and permeabilized with $0.5 \%$ Triton X-100 in PBS for $10 \mathrm{~min}$. After the cells were washed 3 times with PBS, they were blocked with 3\% bovine serum albumin in PBS for $30 \mathrm{~min}$ and incubated with primary antibodies followed by Alexa 488- or Alexa 555-conjugated secondary antibodies (Thermo Fisher Scientific). Stained specimens were mounted with Vectashield mounting medium containing DAPI (Vector Laboratories, Burlingame, CA, 
USA) and examined with a LSM700 laser scanning confocal microscopy and the LSM software ZEN 2012 (Carl Zeiss, Jena, Germany). For determination of fusion indexes, numbers of nuclei in STB-like fused cells and the total numbers of nuclei were counted in 8 to 10 randomly selected microscopic fields in each E-cadherin-stained specimen. Fusion indexes were calculated as the percentages of the total number of nuclei in the STB-like fused cells to the total number of nuclei in the microscopic fields.

\subsection{Statistical Analysis}

Data were analyzed via one-way ANOVA with Bonferroni's multiple comparisons test, or the Mann-Whitney U-test by means of Prism software (Version 7.04, GraphPad Software, San Diego, CA, USA). $p$ values of $<0.05$ were said to be significant.

\section{Results}

\subsection{Upregulation of Serum CRT Levels in Patients with Preeclampsia}

Table 1 summarizes the clinical characteristics of the patients in the present study. We first used Western blotting to determine the CRT protein levels in the samples of placenta (Figure 1a) and serum (Figure 1b) collected from nonpregnant women $(n=6)$, women with gestational age-matched normal pregnancies $(n=6)$, and preeclamptic patients $(n=6)$, who were included in Table 1 . We successfully detected the 55-kDa CRT protein in placental and serum samples. We used cell lysates obtained from BeWo cells as the reference for the CRT protein band [16]. We noted no difference in the CRT levels in placentas from women with normal pregnancies and women with preeclampsia (Figure 1c), but the serum CRT levels were approximately $50 \%$ lower in nonpregnant women and $35 \%$ higher in preeclamptic women than the levels in women with normal pregnancies (Figure 1d). We also determined the CRT levels in the third-trimester placentas of the patients shown in Table 1 by using immunohistochemical analysis (normal placentas $(n=22)$ and preeclamptic placentas $(n=18)$; Figure 1e). In agreement with our previous report [16], the major site of CRT expression was the STB cytoplasm in both normal and preeclamptic placentas (Figure 1e). We also detected CRT in endothelial cells and villous macrophages (Hofbauer cells) in the villous cores, EVTs in the decidua and chorionic membrane, and connective tissue cells in the amnion layer of the external membranes in third-trimester placentas. We noted no difference in IRSs for normal placentas and preeclamptic placentas, a finding that confirmed the immunoblot analysis (Figure 1e).

Data are expressed as means $\pm \mathrm{SD}$; ns, not significant. 
(a)

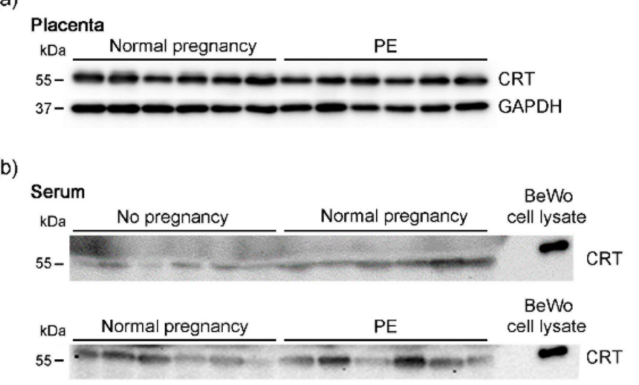

(e)

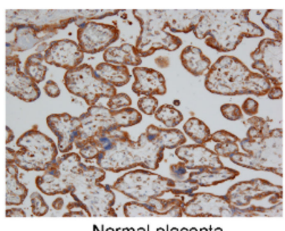
Normal placenta

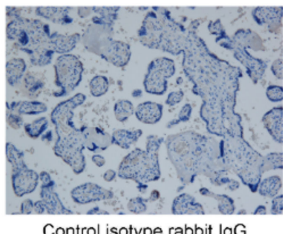

(c)

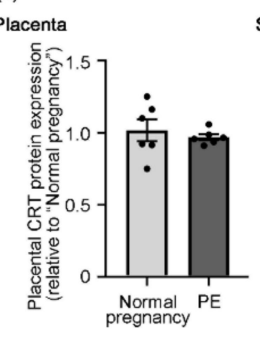

(d)
Serum

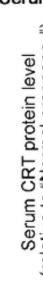

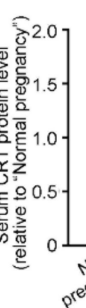

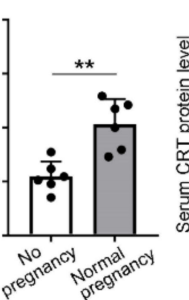

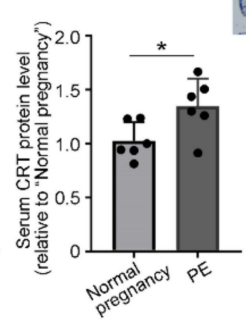
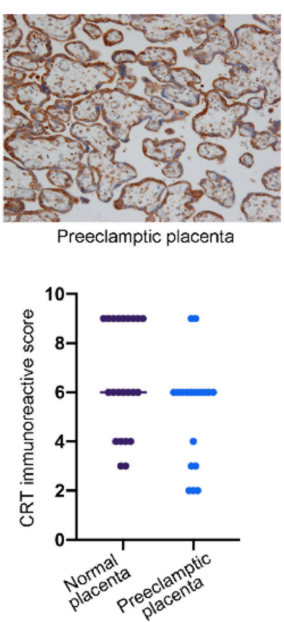

Figure 1. Upregulation of serum CRT levels in patients with preeclampsia. CRT protein levels in placental (a) and serum (b) samples obtained from nonpregnant women $(n=6)$, women with normal pregnancies $(n=6)$, and patients with preeclampsia $(\mathrm{PE} ; \mathrm{n}=6)$ were analyzed by using Western blotting. Cell lysates that were prepared from BeWo cells under conventional culture conditions served as the reference for the CRT-immunoreactive band. GAPDH was used as the loading control in (a). For analysis of serum samples in (b), $100 \mu \mathrm{g}$ of total proteins were loaded in each well. (c,d) Quantitative analysis of the immunoblots in (a) and (b). (e) Representative images of immunohistochemical analysis of CRT in normal placentas $(n=22)$ and preeclamptic placentas $(\mathrm{n}=18)$. The graph provides CRT IRSs. Data are presented as means \pm standard deviation (SD). ${ }^{*} p<0.05 ;{ }^{* *} p<0.01$.

\subsection{Thapsigargin-Induced ER Stress in BeWo Cells}

Because ER stress in placentas has been implicated in the etiology and pathology of human pregnancy complications, including preeclampsia $[29,30]$, we hypothesized that the induction of ER stress would stimulate placental cells to release CRT, which may contribute to increased serum CRT levels in preeclamptic patients (Figure 1b,d). We utilized human choriocarcinoma BeWo cells, which are commonly used as a model of trophoblast differentiation and syncytialization $[5,28]$, and thapsigargin, which is a very popular ER stress inducer and depletes the calcium ion store in the ER, thereby causing ER stress [31]. We treated BeWo cells with thapsigargin $(25-500 \mathrm{nM})$ for $1 \mathrm{~h}$ at $37^{\circ} \mathrm{C}$, after which we replaced the culture media with fresh media and continued the cell culture for $23 \mathrm{~h}$ at $37^{\circ} \mathrm{C}$. We then harvested the cells, induced ER stress, and determined the cytotoxicity of the thapsigargin treatment. The XBP-1 splicing assay [32] confirmed the thapsigargin concentration-dependent induction of ER stress (Figure 2a). Immunoblot analysis of phosphorylated eukaryotic initiation factor- $2 \alpha$ (eIF2 $\alpha)$, another marker of ER stress induction [33], also indicated thapsigargin concentration-dependent induction of ER stress (Figure 2b). We did not observe extracellular release of LDH after thapsigargin treatment, which excluded the possibility of plasma membrane damage (Figure 2c). 
(a)

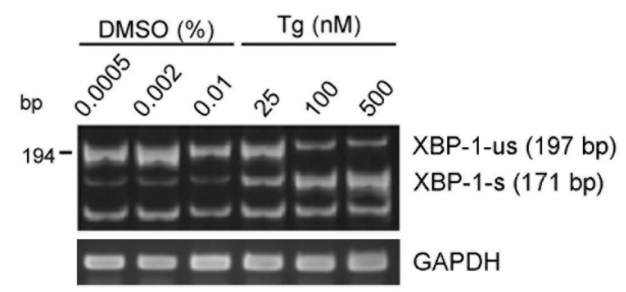

(b)

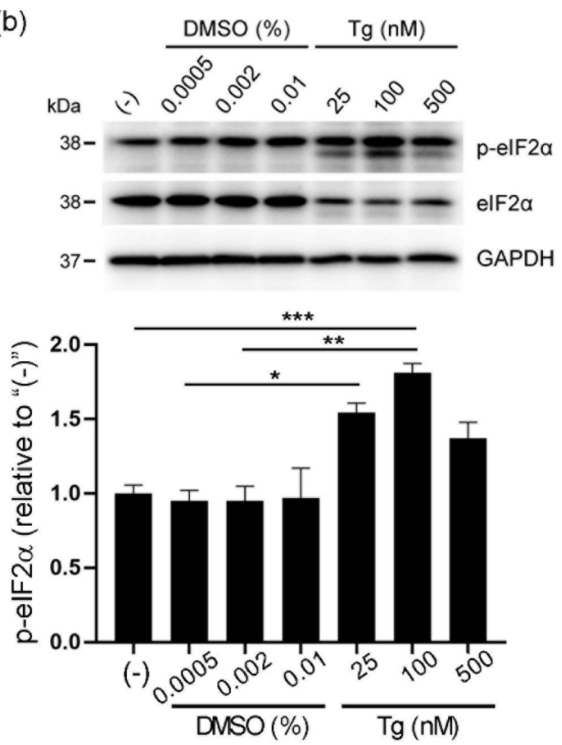

(c)

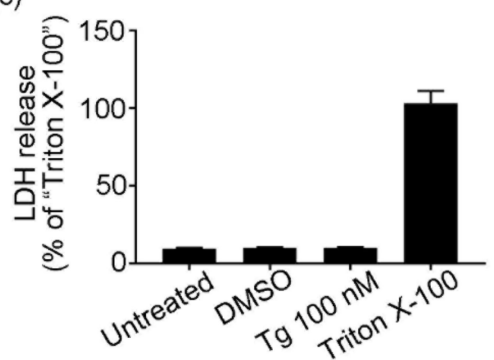

Figure 2. Thapsigargin-induced ER stress in BeWo cells. BeWo cells were treated with thapsigargin $(\mathrm{Tg}, 25-500 \mathrm{nM})$ or DMSO for $1 \mathrm{~h}$ at $37^{\circ} \mathrm{C}$. After samples were washed three times with phosphatebuffered saline (PBS), culture media were replaced with fresh Opti-MEM and cells were cultured for $24 \mathrm{~h}$ at $37^{\circ} \mathrm{C}$. Cells were then harvested, and induction of ER stress and cytotoxicity of thapsigargin treatment were analyzed. (a) mRNAs of XBP-1 and GAPDH were assessed by using RT-PCR. XBP 1-s, spliced fragments of XBP-1; XBP 1-us, unspliced fragments of XBP-1. (b) Expression levels of the ER stress marker phosphorylated eIF2 $\alpha$ (p-eIF2 $\alpha$ ) were analyzed by using Western blotting. GAPDH served as the loading control. The graph shows quantification of p-eIF2 $\alpha$. Data represent means \pm SE $(n=3)$. (c) Cytotoxicity of thapsigargin treatment $(\mathrm{Tg})$ was assessed by means of the LDH release assay. Results are presented as a percentage of the values of $2 \%$ Triton X-100-treated cells, which caused the maximum release via complete membrane disruption. Data represent means $\pm \mathrm{SE}(\mathrm{n}=5)$. ${ }^{*} p<0.05 ;{ }^{* *} p<0.01 ;{ }^{* * *} p<0.001$.

\subsection{Extracellular Release of CRT after Thapsigargin-Induced ER Stress in BeWo Cells}

We next investigated the effect of thapsigargin-induced ER stress on the release of CRT from BeWo cells. We treated BeWo cells with thapsigargin (25-500 $\mathrm{nM}$ ) for $1 \mathrm{~h}$ at $37^{\circ} \mathrm{C}$, after which culture media were replaced with fresh media and cells were cultured for $23 \mathrm{~h}$ at $37^{\circ} \mathrm{C}$. We then harvested the conditioned media and analyzed the CRT levels in the conditioned media. Immunoblots with an anti-CRT antibody showed thapsigargin concentration-dependent extracellular release of CRT from BeWo cells (Figure 3a). Because we did not observe extracellular release of BiP from thapsigargin-treated BeWo cells (Figure 3a), we concluded that ER stress did not induce extracellular release of all ER-resident proteins, that is, this phenomenon was specific to CRT. We also used immunoblot analysis to determine the expression of CRT and other ER-resident proteins including BiP, calnexin, and ERp57 in BeWo cells treated with $100 \mathrm{nM}$ thapsigargin. We detected no alterations in the expression of these proteins including CRT after thapsigargin treatment (Figure 3b). We previously reported that genetic ablation of CRT expression resulted in reduced cell surface localization of E-cadherin and subsequent fusion of BeWo 
cells [16]. In our study here, we detected two bands that corresponded to E-cadherin, similar to bands for epithelial cells whose trafficking of E-cadherin was inhibited by cellular stress (Figure 3b) [34]. As expected, our immunofluorescence analysis showing enhanced and condensed colocalization of E-cadherin and the cis-Golgi marker GM130 confirmed thapsigargin-induced altered E-cadherin subcellular localization (Figure 3c).

(a)

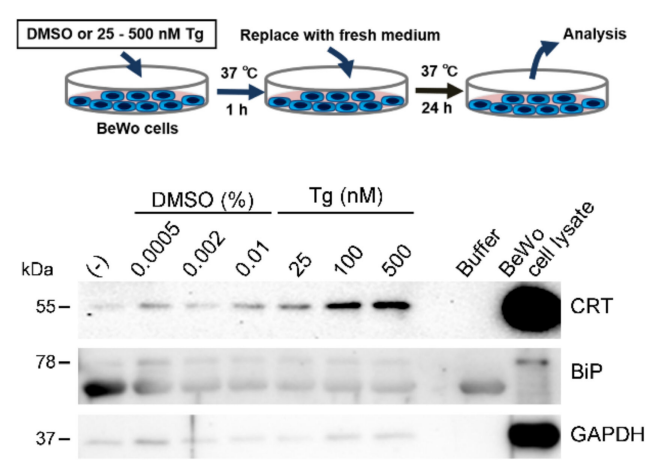

(b)

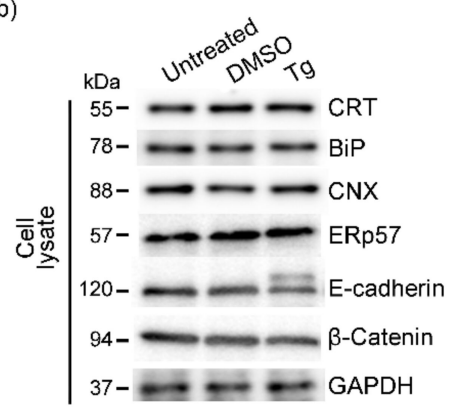

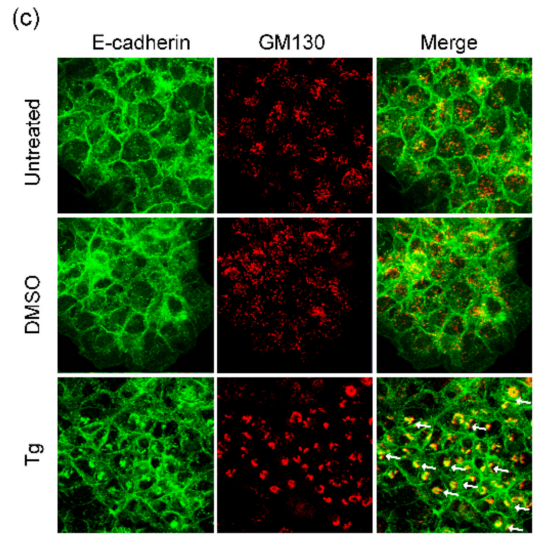

Figure 3. Extracellular release of CRT after thapsigargin-induced ER stress in BeWo cells. (a) BeWo cells were treated with thapsigargin $(\mathrm{Tg})$ or DMSO for $1 \mathrm{~h}$ at $37^{\circ} \mathrm{C}$. After samples were washed three times with PBS, culture media were replaced with fresh Opti-MEM and cells were cultured for $24 \mathrm{~h}$ at $37^{\circ} \mathrm{C}$. Conditioned medium samples were then collected and CRT protein levels were analyzed by means of Western blotting. GAPDH and BiP served as markers for the cytosol and the ER, respectively. (b) Expression of ER-resident proteins in thapsigargin-treated ( $\mathrm{Tg}, 100 \mathrm{nM})$ BeWo cells was analyzed by using Western blotting. GAPDH served as the loading control. (c) DMSO- or thapsigargin-treated (Tg, $100 \mathrm{nM}$ ) BeWo cells were stained with anti-E-cadherin and anti-GM130 antibodies. Arrows point to condensed E-cadherin signals that colocalized with GM130.

\subsection{Forskolin-Induced Syncytialization of BeWo Cells Inhibited by Extracellular CRT}

We also studied the effects of extracellular CRT on the functions of BeWo cells. Because BeWo cells secrete $\beta-h C G$, which is mainly produced by placental STBs and promotes syncytialization in an autocrine-paracrine manner $[35,36]$, we investigated whether extracellular CRT would affect forskolin-induced $\beta$-hCG secretion in BeWo cells. Because we successfully induced ER stress and extracellular release of CRT by $100 \mathrm{nM}$ thapsigargin treatment (Figure 2a,b and Figure 3a), we used $100 \mathrm{nM}$ thapsigargin treatment for further experiments. We treated BeWo cells with $100 \mathrm{nM}$ thapsigargin for $1 \mathrm{~h}$ at $37^{\circ} \mathrm{C}$, after which culture media were replaced with fresh media and cells were cultured for $23 \mathrm{~h}$ at $37^{\circ} \mathrm{C}$. We then collected $\mathrm{Tg}-\mathrm{CM}$ samples and treated fresh BeWo cells with $\mathrm{Tg}-\mathrm{CM}$ in the presence of $80 \mu \mathrm{M}$ forskolin for $24 \mathrm{~h}$ at $37^{\circ} \mathrm{C}$. We successfully obtained CRT-containing Tg-CM by using thapsigargin treatment (Figure 4a). Because we solubilized thapsigargin in dimethyl sulfoxide (DMSO), we prepared DMSO-treated conditioned medium (DMSO-CM) as the control. Figure $4 \mathrm{~b}, \mathrm{c}$ show that treatment with $\mathrm{Tg}-\mathrm{CM}$ markedly suppressed forskolininduced $\beta$-hCG secretion and cell fusion in BeWo cells. Tg-CM-treated BeWo cells showed 
two E-cadherin immunoreactive bands that were similar to those of thapsigargin-treated cells (Figures $3 \mathrm{~b}$ and $4 \mathrm{~b}$ ), which suggests that extracellular CRT may affect subcellular localization of E-cadherin. Immunofluorescence analysis demonstrated enhanced and condensed colocalization of E-cadherin and the cis-Golgi marker, which confirmed the unfavorable effect of extracellular CRT on syncytialization (Figure 4d).

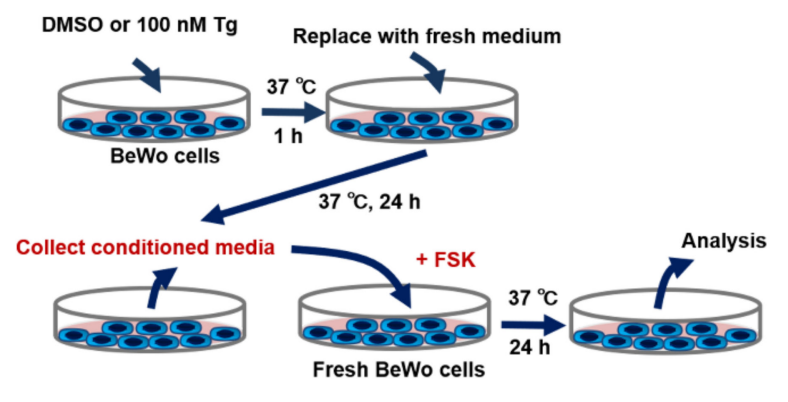

(a)

(b)
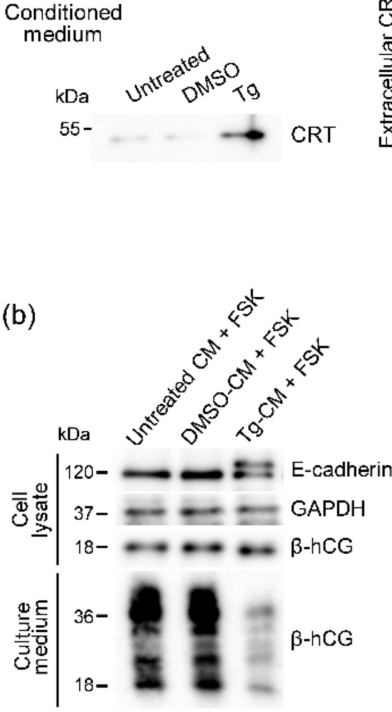
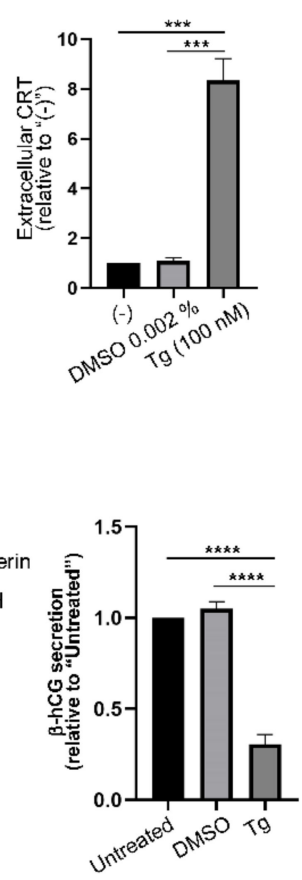

(c)

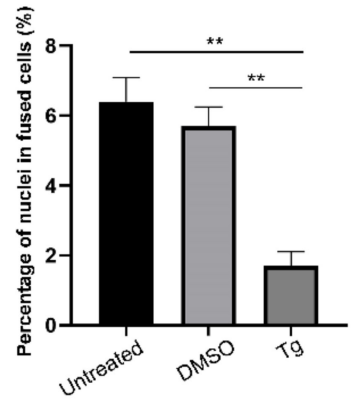

(d)

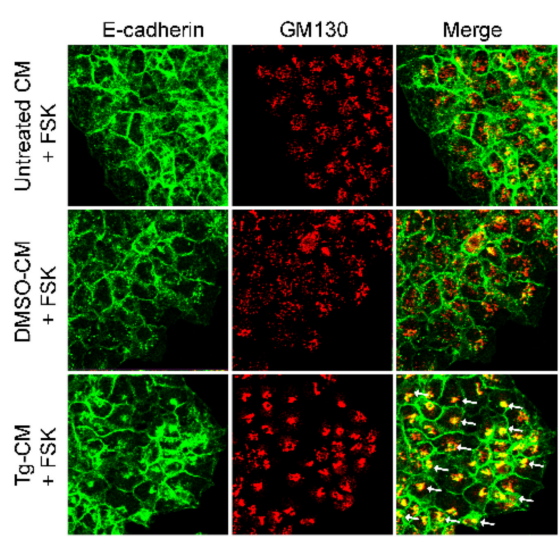

Figure 4. Extracellular CRT-induced inhibition of forskolin-induced syncytialization in BeWo cells. (a) BeWo cells were treated with thapsigargin (Tg) or DMSO for $1 \mathrm{~h}$ at $37^{\circ} \mathrm{C}$. After samples were washed three times with PBS, culture media were replaced with fresh Opti-MEM and cells were cultured for $24 \mathrm{~h}$ at $37^{\circ} \mathrm{C}$. Conditioned medium samples were then collected to obtain DMSO-CM and Tg-CM. Extracellular release of CRT by thapsigargin was confirmed by means of Western blotting. The graph shows quantification of extracellular release of CRT by Tg (100 nM)-treatment. Data represent means $\pm S E(n=3)$. (b) To investigate the effects of extracellular CRT on syncytialization, fresh BeWo cells were treated with DMSO-CM or Tg-CM in the presence of forskolin (FSK, $80 \mu \mathrm{M})$ for $24 \mathrm{~h}$ at $37{ }^{\circ} \mathrm{C}$, and expression of E-cadherin and secretion of $\beta$-hCG were analyzed by using Western blotting. GAPDH served as the loading control. The graph shows quantification of secreted $\beta$-hCG. Data represent means $\pm S E(n=3)$. (c) Effects of Tg-CM treatment on syncytialization was analyzed by means of fusion indexes. Data represent means $\pm S E(n=3)$. (d) Effects of Tg-CM treatment on subcellular localization of E-cadherin were analyzed by means of immunofluorescence with anti-E-cadherin and anti-GM130 antibodies. Arrows point to condensed E-cadherin signals that colocalized with GM130. ${ }^{* *} p<0.01$; $^{* * *} p<0.001$; $^{* * * *} p<0.0001$. 


\subsection{Elimination of Harmful Effects of Tg-CM on BeWo Cells by Means of CRT Immunodepletion}

Lastly, we immunodepleted CRT proteins in Tg-CM by using an anti-CRT antibody and Dynabeads that were conjugated with protein G (CRT-depleted CM). By using immunoblot analysis, we found that CRT-depleted CM lacked the suppressive effect of $\mathrm{Tg}-\mathrm{CM}$ on forskolin-induced $\beta$-hCG secretion and cell fusion, which strongly supported the adverse effect of extracellular CRT on syncytialization (Figure 5a,b). In addition, enhanced and condensed colocalization patterns of E-cadherin and GM130 disappeared in CRT-depleted CM-treated BeWo cells (Figure 5c). Together, our results demonstrated the detrimental effects of ER stress-induced extracellular release of CRT on CTB functions such as $\beta$-hCG secretion and syncytialization, thus leading to the ER stress-induced development of preeclampsia.

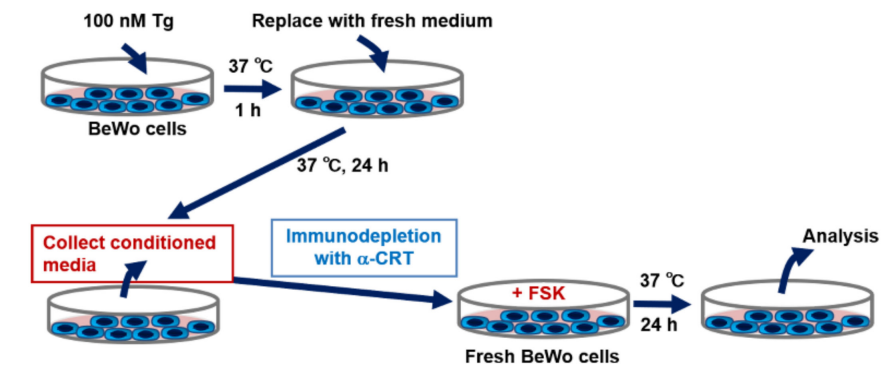

(a)

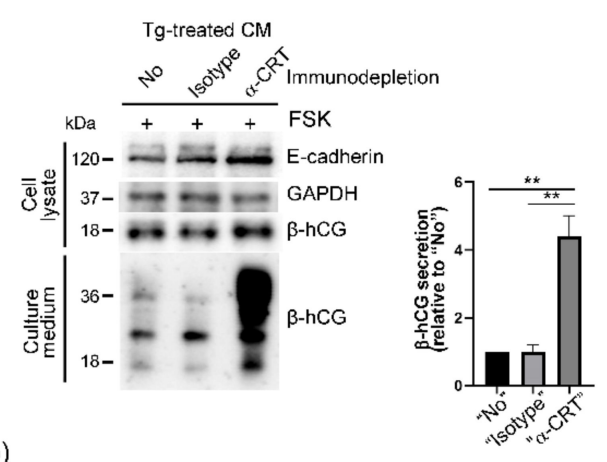

(b)

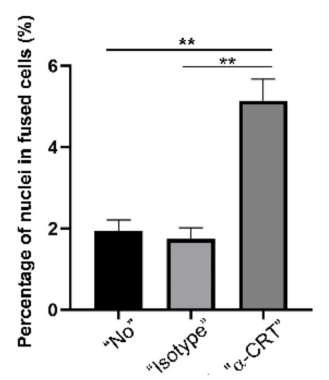

(c)

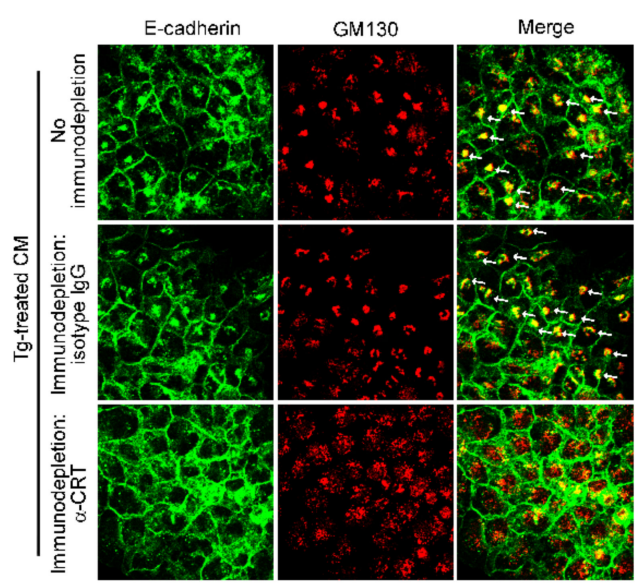

Figure 5. Elimination of detrimental effects of Tg-CM on BeWo cells by CRT immunodepletion. (a) BeWo cells were treated with thapsigargin $(\mathrm{Tg})$ for $1 \mathrm{~h}$ at $37^{\circ} \mathrm{C}$. After samples were washed three times with PBS, culture media were replaced with fresh Opti-MEM and cells were cultured for $24 \mathrm{~h}$ at $37^{\circ} \mathrm{C}$. Conditioned medium samples were then collected to obtain Tg-CM. CRT in Tg-CM was immunodepleted by using an anti-CRT antibody and Dynabeads with protein G. Fresh BeWo cells were then treated with Tg-CM or CRT-depleted Tg-CM in the presence of forskolin (FSK, $80 \mu \mathrm{M})$ for $24 \mathrm{~h}$ at $37^{\circ} \mathrm{C}$, and expression of E-cadherin and secretion of $\beta$-hCG were analyzed via Western blotting. The graph shows quantification of secreted $\beta$-hCG. Data represent means \pm SE $(n=3)$. (b) Effects of CRT immunodepletion from Tg-CM on syncytialization was analyzed by means of fusion indexes. Data represent means $\pm \mathrm{SE}(\mathrm{n}=3)$. (c) Fresh BeWo cells were treated with Tg-CM or CRT-depleted Tg-CM in the presence of forskolin $(80 \mu \mathrm{M})$ for $24 \mathrm{~h}$ at $37^{\circ} \mathrm{C}$, and subcellular localization of E-cadherin was analyzed by using immunofluorescence with anti-E-cadherin and anti-GM130 antibodies. Arrows point to condensed E-cadherin signals that colocalized with GM130. ${ }^{* *} p<0.01$. 


\section{Discussion}

CRT is an ER-resident molecular chaperone that is ubiquitously expressed throughout the body. In addition, non-ER functions of CRT have been implicated in many physiological and pathological processes, including wound healing, immunity, cell development, proliferation, differentiation, malignancy, and tumor progression $[14,37,38]$. In the ER, CRT plays important roles not only in the proper folding of newly synthesized proteins and glycoproteins but also in homeostatic regulation of calcium levels in the cytosol and ER [14,39]. The human placenta is one site with high CRT expression during pregnancy $[40,41]$, which suggests a role of CRT in placentation and maintenance of pregnancy. We previously showed that CRT expression by placental cells was required for trophoblast invasion and trophoblast syncytialization $[15,16]$, which supported the importance of CRT in pregnancy. CRT may be released from cells under certain conditions, such as injury or death [42]. Although CRT at the cell surface reportedly served as a marker of phagocytic clearance [17,18], the functions of extracellular CRT in placentas have remained unclear. In our study here, we found that CRT was released from cells because of ER stress and that extracellular CRT possessed certain biological functions such as reduction of forskolin-induced $\beta$-hCG secretion and modification of membrane localization of E-cadherin. Our results showing that extracellularly released CRT inhibited forskolin-induced syncytialization will aid our understanding of the molecular functions of CRT beyond that of an ER chaperone. A previous study reported that a tumor-homing peptide recognized CRT at the placental membrane [6], which suggested a potential non-ER function of CRT in the targeted delivery of materials to the placenta. Our study here, however, is the first to report a non-ER extracellular function of CRT-involvement in the development of preeclampsia. Tong et al. identified CRT as one component of trophoblast extracellular microvesicles [43]. Because extracellular vesicles such as exosomes and microvesicles are involved in cell-cell communication in that they transfer biomolecules including microRNAs and proteins [44], the role of CRT on or in extracellular vesicles warrants future investigation.

ER stress is one major risk factor for preeclampsia, as suggested by the upregulation of several ER stress markers in placentas with both intrauterine growth retardation and preeclampsia compared with placentas with intrauterine growth retardation alone [45, 46]. Increased ER stress may lead to reduced proliferation and enhanced apoptosis of trophoblasts [45], but the precise mechanism of how ER stress results in preeclampsia is unknown. Gu et al. reported a significant increase in blood CRT levels, but not in placental CRT levels, in women with normal pregnancies compared with nonpregnant women [13]. In the present study, blood samples from women with normal pregnancies had significantly higher CRT levels than samples from nonpregnant women, and blood samples from preeclamptic women demonstrated further marked increases in CRT levels compared to those from women with normal pregnancies. Furthermore, BeWo cells released CRT in response to ER stress, but not under general culture conditions without ER stress induction, and the extracellular CRT prevented forskolin-induced syncytialization. Thus, our results provide evidence that excess extracellular CRT may have adverse effects on placental development and cause dysfunctional placentation that may lead to preeclampsia.

The molecular mechanism by which extracellular CRT suppressed forskolin-induced $\beta$-hCG release is as yet unclear. In extracellular CRT-treated BeWo cells, we observed an E-cadherin band in addition to the mature $120 \mathrm{kDa}$ form, which may correspond to the pro-E-cadherin [34], and extracellular CRT induced E-cadherin to accumulate in the GM130-positive cis-Golgi. Although the accumulation of E-cadherin in the cis-Golgi was similar to that reported in our previous study of BeWo cells whose CRT was genetically depleted by stable expression of short hairpin RNA against CRT [16], we did not observe the additional E-cadherin band in that study. Thus, it seems to be unlikely that extracellular CRT interfered with the chaperone function of CRT on E-cadherin, and our current results suggest another role of extracellular CRT in determining subcellular localization of Ecadherin. Elucidating the details of the detrimental effects of extracellular CRT is a future challenge. 
The source of the increased serum CRT in preeclamptic patients is also not fully clarified. Gu et al. suggested that the placenta may be a major source of circulating CRT in pregnancy [13]. In view of the induction of ER stress in preeclamptic placentas and our results showing the extracellular release of CRT by an ER stress inducer, the placenta may indeed be the major source of increased circulating CRT in preeclamptic serum. However, our immunohistochemical and immunoblot analyses of human placental tissues demonstrated no significant differences between placental CRT protein levels in women with normal pregnancies and in patients with preeclampsia. Thus, we cannot discount the possibility that tissues and organs other than the placenta may contribute to circulating CRT levels.

\section{Conclusions}

In summary, we found increased CRT levels in samples of serum from preeclamptic patients but not in samples of placentas. The results of the cell-based assays supported the pathological roles of extracellular CRT in preeclampsia. Our findings are thus important for the prediction, prevention, and treatment of preeclampsia. We showed that ER stress, a major risk factor for preeclampsia, induced extracellular rerelease of CRT and that the extracellular CRT prevented forskolin-induced syncytialization in CTB model cells, but elucidating the precise molecular mechanisms of these data deserves additional study.

Supplementary Materials: The following are available online at https:/ /www.mdpi.com/article/10 .3390/cells10061305/s1, Table S1 Protein concentrations of serum samples.

Author Contributions: N.I., M.I., M.Y., I.M., N.K., N.T. and M.T. performed the experiments; N.I., S.-i.M. and K.I. analyzed the human tissues; N.I., K.N. and Y.I. designed the study. N.I. and K.N. interpreted the data and wrote the paper. K.N and Y.I. take full responsibility for the entire manuscript. All authors have read and agreed to the published version of the manuscript.

Funding: This work was partly supported by Grants-in-Aid from the Ministry of Education, Culture, Sports, Science and Technology (MEXT)/Japan Society for the Promotion of Science (JSPS) (19K09784 to M.I., 18K16809 to M.Y., and 20K18228 and JP18K16776 to N.I.). This study was also partly supported by an internal grant from Wakayama Medical University (Tokutei-kenkyu-zyosei 2019 and 2020). This study was partly supported by the Japan Society for the Study of Hypertension in Pregnancy (to N.I.).

Institutional Review Board Statement: This study was approved by the Ethics Committee of Wakayama Medical University (authorization number:1690) and was conducted in accordance with the tenets of the Declaration of Helsinki. All patients provided written informed consent for the use of their tissue samples.

Informed Consent Statement: Informed consent was obtained from all subjects involved in the study.

Data Availability Statement: The data presented in this study are openly available in FigShare at https:/ / doi.org/10.6084/m9.figshare.14658768.

Conflicts of Interest: The authors declare no conflict of interest.

\section{References}

1. Bischof, P.; Irminger-Finger, I. The human cytotrophoblastic cell, a mononuclear chameleon. Int. J. Biochem. Cell Biol. 2005, 37, 1-16. [CrossRef] [PubMed]

2. Moser, G.; Orendi, K.; Gauster, M.; Siwetz, M.; Helige, C.; Huppertz, B. The art of identification of extravillous trophoblast. Placenta 2011, 32, 197-199. [CrossRef]

3. Eaton, B.; Contractor, S. In Vitro Assessment of Trophoblast Receptors and Placental Transport Mechanisms; Blackwell Scientific Publication: London, UK, 1993; pp. 471-503.

4. $\quad$ Ogren, L.; Talamentes, F. The Placenta as an Endocrine Organ: Polypeptides; Raven Press: New York, NY, USA, $1994 ;$ pp. 875-945.

5. Gauster, M.; Moser, G.; Orendi, K.; Huppertz, B. Factors involved in regulating trophoblast fusion: Potential role in the development of preeclampsia. Placenta 2009, 30, S49-S54. [CrossRef]

6. Acien, P.; Lloret, G.; Lloret, M. Perinatal morbidity and mortality in pregnancy hypertensive disorders: Prognostic value of the clinical and laboratory findings. Int. J. Gynaecol. Obs. 1990, 32, 229-235. [CrossRef] 
7. Brown, M.A.; Hague, W.M.; Higgins, J.; Lowe, S.; McCowan, L.; Oats, J.; Rowan, J.A.; Walters, B.N.J. The detection, investigation and management of hypertension in pregnancy: Executive summary. Aust. N. Z. J. Obs. Gynaecol. 2000, 40, 133-138. [CrossRef] [PubMed]

8. $\quad$ Lian, I.A.; Løset, M.; Mundal, S.B.; Fenstad, M.H.; Johnson, M.P.; Eide, I.P.; Austgulen, R.; Bjørge, L.; Freed, K.A.; Moses, E.K. Increased endoplasmic reticulum stress in decidual tissue from pregnancies complicated by fetal growth restriction with and without pre-eclampsia. Placenta 2011, 32, 823-829. [CrossRef] [PubMed]

9. Mizuuchi, M.; Cindrova-Davies, T.; Olovsson, M.; Charnock-Jones, D.S.; Burton, G.J.; Yung, H.W. Placental endoplasmic reticulum stress negatively regulates transcription of placental growth factor via ATF4 and ATF6beta: Implications for the pathophysiology of human pregnancy complications. J. Pathol. 2016, 238, 550-561. [CrossRef] [PubMed]

10. Guo, M.Y.; Wang, H.; Chen, Y.H.; Xia, M.Z.; Zhang, C.; Xu, D.X. N-acetylcysteine alleviates cadmium-induced placental endoplasmic reticulum stress and fetal growth restriction in mice. PLoS ONE 2018, 13, e0191667. [CrossRef]

11. Fu, J.; Zhao, L.; Wang, L.; Zhu, X. Expression of markers of endoplasmic reticulum stress-induced apoptosis in the placenta of women with early and late onset severe pre-eclampsia. Taiwan J. Obs. Gynecol. 2015, 54, 19-23. [CrossRef] [PubMed]

12. Shi, Z.; Hou, W.; Hua, X.; Zhang, X.; Liu, X.; Wang, X.; Wang, X. Overexpression of calreticulin in pre-eclamptic placentas: Effect on apoptosis, cell invasion and severity of pre-eclampsia. Cell Biochem. Biophys. 2012, 63, 183-189. [CrossRef] [PubMed]

13. Gu, V.Y.; Wong, M.H.; Stevenson, J.L.; Crawford, K.E.; Brennecke, S.P.; Gude, N.M. Calreticulin in human pregnancy and pre-eclampsia. Mol. Hum. Reprod. 2008, 14, 309-315. [CrossRef] [PubMed]

14. Michalak, M.; Groenendyk, J.; Szabo, E.; Gold, L.I.; Opas, M. Calreticulin, a multi-process calcium-buffering chaperone of the endoplasmic reticulum. Biochem. J. 2009, 417, 651-666. [CrossRef]

15. Yamamoto, M.; Ikezaki, M.; Toujima, S.; Iwahashi, N.; Mizoguchi, M.; Nanjo, S.; Minami, S.; Ihara, Y.; Ino, K. Calreticulin is involved in invasion of human extravillous trophoblasts through functional regulation of integrin beta1. Endocrinology 2017, 158, 3874-3889. [CrossRef]

16. Iwahashi, N.; Ikezaki, M.; Matsuzaki, I.; Yamamoto, M.; Toujima, S.; Murata, S.I.; Ihara, Y.; Ino, K. Calreticulin regulates syncytialization through control of the synthesis and transportation of e-cadherin in bewo cells. Endocrinology 2019, 160, 359-374. [CrossRef] [PubMed]

17. Gardai, S.J.; McPhillips, K.A.; Frasch, S.C.; Janssen, W.J.; Starefeldt, A.; Murphy-Ullrich, J.E.; Bratton, D.L.; Oldenborg, P.; Michalak, M.; Henson, P.M. Cell-surface calreticulin initiates clearance of viable or apoptotic cells through trans-activation of LRP on the phagocyte. Cell 2005, 123, 321-334. [CrossRef]

18. Obeid, M.; Tesniere, A.; Ghiringhelfi, F. Calreticulin exposure dictates the immunogenicity of cancer cell death. Nat. Med. 2007, 13, 54-61. [CrossRef] [PubMed]

19. Nanney, L.B.; Woodrell, C.D.; Greives, M.R.; Cardwell, N.L.; Pollins, A.C.; Bancroft, T.A.; Chesser, A.; Michalak, M.; Rahman, M.; Gold, L.I.; et al. Calreticulin enhances porcine wound repair by diverse biological effects. Am. J. Pathol. 2008, 173, 610-630. [CrossRef] [PubMed]

20. Coppolino, M.G.; Dedhar, S. Ligand-specific, transient interaction between integrins and calreticulin during cell adhesion to extracellular matrix proteins is dependent upon phosphorylation/dephosphorylation events. Biochem. J. 1999, 340, 41-50. [CrossRef]

21. Coppolino, M.G.; Woodside, M.J.; Demaurex, N.; Grinstein, S.; St-Arnaud, R.; Dedhar, S. Calreticulin is essential for integrinmediated calcium signalling and cell adhesion. Nature 1997, 386, 843-847. [CrossRef] [PubMed]

22. Orr, A.W.; Pedraza, C.E.; Pallero, M.A.; Elzie, C.A.; Goicoechea, S.; Strickland, D.K.; Murphy-Ullrich, J.E. Low density lipoprotein receptor-related protein is a calreticulin coreceptor that signals focal adhesion disassembly. J. Cell Biol. 2003, 161, 1179-1189. [CrossRef] [PubMed]

23. Orr, A.W.; Pallero, M.A.; Murphy-Ullrich, J.E. Thrombospondin stimulates focal adhesion disassembly through Gi- and phosphoinositide 3-kinase-dependent ERK activation. J. Biol. Chem. 2002, 277, 20453-20460. [CrossRef]

24. Gold, L.I.; Eggleton, P.; Sweetwyne, M.T.; Van Duyn, L.B.; Greives, M.R.; Naylor, S.M.; Murphy-Ullrich, J.E. Calreticulin: Non-endoplasmic reticulum functions in physiology and disease. FASEB J. 2010, 24, 665-683. [CrossRef] [PubMed]

25. Crawford, K.E.; Kalionis, B.; Stevenson, J.L.; Brennecke, S.P.; Gude, N.M. Calreticulin has opposing effects on the migration of human trophoblast and myometrial endothelial cells. Placenta 2012, 33, 416-423. [CrossRef] [PubMed]

26. Coutifaris, C.; Kao, L.C.; Sehdev, H.M.; Chin, U.; Babalola, G.O.; Blaschuk, O.W.; Strauss, J.F. E-cadherin expression during the differentiation of human trophoblasts. Development 1991, 113, 767-777. [CrossRef] [PubMed]

27. Kohlberger, P.D.; Breitenecker, F.; Kaider, A.; Losch, A.; Gitsch, G.; Breitenecker, G.; Kieback, D.G. Modified true-color computerassisted image analysis versus subjective scoring of estrogen receptor expression in breast cancer: A comparison. Anticancer Res. 1999, 19, 2189-2193. [PubMed]

28. Drewlo, S.; Baczyk, D.; Dunk, C.; Kingdom, J. Fusion assays and models for the trophoblast. Methods Mol. Biol. 2008, 475, 363-382. [CrossRef]

29. Zamudio, S.; Plamer, S.K.; Regensteiner, J.G.; Moore, L.G. High altitude and hypertension during pregnancy. Am. J. Hum. Biol. 1995, 7, 183-193. [CrossRef]

30. Soothill, P.W.; Nicolaides, K.H.; Rodeck, C.H. Effect of anaemia on fetal acid-base status. Br. J. Obs. Gynaecol. 1987, 94, 880-883. [CrossRef] [PubMed] 
31. Hiramatsu, N.; Kasai, A.; Hayakawa, K.; Yao, J.; Kitamura, M. Real-time detection and continuous monitoring of ER stress in vitro and in vivo by ES-TRAP: Evidence for systemic, transient ER stress during endotoxemia. Nucleic Acids Res. 2006, 34 , e93. [CrossRef]

32. Yoshida, H.; Matsui, T.; Yamamoto, A.; Okada, T.; Mori, K. XBP1 mRNA is induced by ATF6 and spliced by IRE1 in response to ER stress to produce a highly active transcription factor. Cell 2001, 107, 881-891. [CrossRef]

33. Ron, D. Translational control in the endoplasmic reticulum stress response. J. Clin. Investig. 2002, 110, 1383-1388. [CrossRef]

34. Geng, F.; Zhu, W.; Anderson, R.A.; Leber, B.; Andrews, D.W. Multiple post-translational modifications regulate E-cadherin transport during apoptosis. J. Cell Sci. 2012, 125, 2615-2625. [CrossRef]

35. Pidoux, G.; Gerbaud, P.; Tsatsaris, V.; Marpeau, O.; Ferreira, F.; Meduri, G.; Guibourdenche, J.; Badet, J.; Evain-Brion, D.; Frendo, J.L. Biochemical characterization and modulation of LH/CG-receptor during human trophoblast differentiation. J. Cell. Physiol. 2007, 212, 26-35. [CrossRef]

36. Shi, Q.J.; Lei, Z.M.; Rao, C.V.; Lin, J. Novel role of human chorionic gonadotropin in differentiation of human cytotrophoblasts. Endocrinology 1993, 132, 1387-1395. [CrossRef] [PubMed]

37. Wang, W.A.; Groenendyk, J.; Michalak, M. Calreticulin signaling in health and disease. Int. J. Biochem. Cell Biol. 2012, $44,842-846$. [CrossRef] [PubMed]

38. Fucikova, J.; Spisek, R.; Kroemer, G.; Galluzzi, L. Calreticulin and cancer. Cell Res. 2021, 31, 5-16. [CrossRef] [PubMed]

39. Kozlov, G.; Gehring, K. Calnexin cycle-Structural features of the ER chaperone system. FEBS J. 2020, 287, 4322-4340. [CrossRef] [PubMed]

40. Hojrup, P.; Roepstorff, P.; Houen, G. Human placental calreticulin characterization of domain structure and post-translational modifications. Eur. J. Biochem. 2001, 268, 2558-2565. [CrossRef]

41. Crawford, K.E.; Stevenson, J.L.; Wlodek, M.E.; Gude, N.M. No change in calreticulin with fetal growth restriction in human and rat pregnancies. Placenta 2013, 34, 1066-1071. [CrossRef]

42. Basu, S.; Binder, R.J.; Suto, R.; Anderson, K.M.; Srivastava, P.K. Necrotic but not apoptotic cell death releases heat shock proteins, which deliver a partial maturation signal to dendritic cells and activate the NF-kappa B pathway. Int. Immunol. 2000, 12, 1539-1546. [CrossRef]

43. Tong, M.; Kleffmann, T.; Pradhan, S.; Johansson, C.L.; DeSousa, J.; Stone, P.R.; James, J.L.; Chen, Q.; Chamley, L.W. Proteomic characterization of macro-, micro- and nano-extracellular vesicles derived from the same first trimester placenta: Relevance for feto-maternal communication. Hum. Reprod. 2016, 31, 687-699. [CrossRef] [PubMed]

44. Tkach, M.; Thery, C. Communication by extracellular vesicles: Where we are and where we need to go. Cell 2016, 164, 1226-1232. [CrossRef] [PubMed]

45. Burton, G.J.; Yung, H.W.; Cindrova-Davies, T.; Charnock-Jones, D.S. Placental endoplasmic reticulum stress and oxidative stress in the pathophysiology of unexplained intrauterine growth restriction and early onset preeclampsia. Placenta 2009, 30 (Suppl. SA), S43-S48. [CrossRef] [PubMed]

46. Yung, H.W.; Calabrese, S.; Hynx, D.; Hemmings, B.A.; Cetin, I.; Charnock-Jones, D.S.; Burton, G.J. Evidence of placental translation inhibition and endoplasmic reticulum stress in the etiology of human intrauterine growth restriction. Am. J. Pathol. 2008, 173, 451-462. [CrossRef] [PubMed] 